\title{
Pautes de consum i condicions de vida dels treballadors de la terra a partir dels inventaris post mortem a Catalunya: el cas de la Selva (1750-1805) Consumption patterns and living conditions of land workers from after-death inventories in Catalonia: the case of La Selva (1750-1805)
}

Josep Mas Ferrer ${ }^{1}$

\section{Resum}

En el present estudi es mostra l'anàlisi de prop d'un centenar d'inventaris post mortem d'individus etiquetats com a treballadors de la terra, redactats en notaries selvatanes al llarg de la segona meitat del segle xviII, en tres talls cronològics concrets: 1750-1755, 1775-1780 i $1800-1805$.

L'objectiu és explorar l'evolució de les seves pautes de consum, així com la de les possibilitats d'accés a la propietat de la terra. També reflexionem sobre els processos de diferenciació social i el sorgiment d'una etiqueta nova per identificar els treballadors de la terra enriquits: els menestrals.

Paraules clau: segle xviI, inventaris, treballadors de la terra, menestrals, consum, condicions de vida, propietat de la terra.

\begin{abstract}
This study presents an analysis of around one hundred notarised after-death inventories of individuals classified as land workers in the La Selva area during the second half of the 18th century, in three specific periods: 1750-1755, 1775-1780 and 1800-1805.

The purpose of this work is to explore the evolution of their consumption patterns, as well as their possibilities of access to property. Additionally, we consider the procedures

1. ORCID 0000-0002-5382-5263. Universitat de Girona. Adreça electrònica: josep.masferrer@udg.edu. Aquest treball s'emmarca dins el projecte de recerca «¿Cambio social sin grupos sociales? El seguimiento de trayectorias colectivas en el pasado desde una perspectiva racional (siglos XIV-XX)» (PGC2018-096350-B-I00), finançat pel Ministeri de Ciència, Innovació i Universitats.
\end{abstract}

Rebut: XI/2020. Avaluat: I/2021. Versió definitiva: II/2021. 
of social differentiation and the emergence of a new label used to identify skilled land workers: menestrals.

Keywords: $18^{\text {th }}$ century, inventories, land workers, consumption, living conditions, property.

Hi ha prou consens historiogràfic avui en dia en el fet que el segle XviII (i en especial la segona meitat) fou un període de caiguda del poder adquisitiu i especialment dels salaris reals, que es veieren estancats al mateix temps que els preus no paraven d'augmentar. ${ }^{2} \mathrm{La}$ regió de Girona, no absenta d'aquest context, presenta algunes peculiaritats, ja que, segons investigacions recents, tot sembla indicar que al llarg de les darreres dècades del segle xviII visqué un període de puixança i crescuda econòmica, especialment dinàmic entre les classes treballadores, fet que comportà fins i tot el naixement d'una nova etiqueta socioprofessional per identificar els treballadors de la terra enriquits, la de «menestral», ${ }^{3}$ en la mateixa època en què n'apareixia també una per a aquells pagesos de mas igualment enriquits, la d' «hisendat». ${ }^{4}$

Independentment de quina fos l'evolució de salaris, preus, dots o qualsevol altre indicador quantificable, el que sí que s'observa arreu en aquesta època és una transformació de les pautes de consum domèstic. Una autèntica revolució en els gustos, les modes i els patrons de compra que feu penetrar en les llars de classe mitjana tota una sèrie de béns que fins llavors eren considerats luxosos i només estaven a l'abast dels més benestants; al mateix temps, entre les famílies més humils començaren a aparèixer tots aquells béns que fins llavors es podrien considerar de semiluxe i que d'aleshores ençà fins als nostres dies han passat a ser d'ús quotidià (com les forquilles o els tovallons, per exemple).

Aquesta aparent dicotomia entre poder adquisitiu i consum va obrir de ple el debat historiogràfic ${ }^{5}$ al voltant de conceptes clau com el de revolució del consum ${ }^{6}$ (i revolució de les aparences) $)^{7}$ o el de revolució industriosa, que consistiria a treballar més per suplir

2. Elaborar un llistat bibliogràfic per al debat al voltant de l'evolució dels salaris reals en la societat europea preindustrial, especialment ben estudiat per la historiografia anglosaxona, resultaria una relació (quasi) infinita. Per citar alguns dels més rellevants i publicats en les dues darreres dècades, vegeu els molts treballs de Robert C. Allen (a tall d'exemple: 2000: 1-25; 2001: 411-447; 2009; 2011: 711-729; 2015: 1-22), de Gregory Clark (2001: 477-505; 2005: 1307-1340; 2007: 97-136), de Hans J. Voth (2000; 2001: 1065-1082) o els més recents de Humphries i Weisdorf (2019: 2867-2887), entre d'altres.

3. Congost (2007a: 133-154; 2014: 165-191) i Congost i Ros (2013: 273-306).

4. Congost (1997: 51-72).

5. Vegeu una síntesi sobre aquest debat i la seva relació amb l'ús dels inventaris post mortem en la introducció que fa Belén Moreno (2018: 9-16) de l'obra collectiva que ella mateixa edità i que porta per títol Els inventaris post-mortem: Una font per a la història social. La introducció de Bartolomé Yun (1999: 9-23) a l'obra dirigida per ell mateix i per Jaume Torras Consumo, condiciones de vida y comercialización: Cataluña y Castilla, siglos xVI-XIX, també aborda i sintetitza aquest debat i en proposa alguns nous plantejaments.

6. Vegeu, per exemple, les obres de McKendrick, Brewer i Plumb (1982), Weatherill (1988) i també Brewer i Porter (1993).

7. Roche (1989). 
la pèrdua de poder adquisitiu i així poder consumir més. Segons aquesta tesi, els ciutadans, atrets per un ímpetu consumista, haurien renunciat, voluntàriament, a una part del temps que dedicaven a l'oci per tal de treballar més, de manera més intensiva i més orientada al mercat. ${ }^{8}$

Es tracta d'una discussió historiogràfica, no exempta d'un cert rerefons ideològic, que pivota a l'entorn d'un dels debats clau de l'economia: entendre (i interpretar) les transformacions que succeirren a la darreria de l'era preindustrial i que, per tant, són el motor i l'explicació del com, l'on i el perquè de la industrialització i del desenvolupament econòmic modern. Dit en altres paraules, interpretar el comportament de la societat europea del llarg segle xviII hauria de permetre entendre una mica millor les causes i els motius de la gran divergència ${ }^{9}$ que succeí entre el món occidental i la resta.

No pretenem, malauradament, entrar en aquest interessant debat, ja que representaria una extralimitació pel que fa a les pretensions d'aquest treball i els coneixements de qui el subscriu. El que presentem a continuació és un petit estudi de cas a partir dels inventaris post mortem relatius a treballadors de la terra i escripturats a les diverses notaries de l'àmbit territorial de la comarca de la Selva en tres talls cronològics concrets: 1750-1755, 1775-1780 i 1800-1805. .10,11 L'objectiu d'aquest treball és veure quines foren les pautes de consum i d'adquisició de béns mobles i immobles al llarg d'aquesta complexa i clau segona meitat del segle xviII. Ho fem partint del supòsit que si realment en aquest període s'hagués produit una transformació de la manera de treballar, produir i consumir, això s'hauria de veure especialment reflectit en aquells collectius socioprofessionals que depenien més directament dels salaris i, per tant, de la «venda» de la seva força de treball i capacitat productiva: els treballadors de la terra.

En analitzar el moviment dels dots a l'interior de la comarca de la Selva al llarg de la segona meitat del segle xviII, ${ }^{12} \mathrm{com}$ a indicador per aproximar-nos al nivell de riquesa i a les

8. Concepte exposat inicialment per Jan De Vries (1994: 249-270). Més endavant hi dedica un llibre sencer, on ho defineix com un procés a través del qual «[la] Europa noroccidental y la Norteamérica británica experimentaron una "revolución industriosa" durante el largo siglo xviI, de 1650 a 1850, más o menos, en la que un número creciente de hogares realizaron una redistribución de sus recursos productivos (el tiempo de sus miembros, principalmente) de formas que incrementaron a la vez la oferta de actividades orientadas al mercado que permitían ganar dinero y la demanda de los bienes ofrecidos en el mercado (De Vries 2009: 24). Com a contrapunt a la hipòtesi de Jan de Vries, vegeu la ressenya d'aquesta obra que feu Jaume Torras (2010: 181-183), així com el llibre, publicat recentment en català, de Julie Marfany (2020), on l'autora compara les tesis de De Vries per a l'Europa nord-occidental amb el cas català a través de l'estudi d'un nucli protoindustrial (situat dins una regió vitícola): Igualada.

9. Sobre aquest concepte, vegeu Pomeranz (2000) i també la síntesi que en fa Allen (2013: 11-28). Vegeu un enfocament i una visió diferent d'aquest procés a Williamson (2012) i a Fontana (2019).

10. Els protocols notarials anteriors a l'any 1800 es troben dipositats a l'Arxiu Històric de Girona i els posteriors a aquesta data es localitzen a l'Arxiu Comarcal de la Selva. Les fonts per a l'elaboració de les taules i els gràfics que mostrem al llarg del treball són aquests protocols, excepte els casos en què s'especifiqui el contrari.

11. La magnitud total de la mostra és de 91 inventaris, distribuïts de la manera següent: 28 inventaris per al període 1750-1755, 35 per als anys 1775-1780 i de nou 28 inventaris per al lapse 1800-1805.

12. Ens referim al treball final de màster inèdit de Mas (2016a: 18), que donà lloc a l'article publicat als Quaderns de la Selva aquell mateix any (Mas 2016b: 71-85). 
desigualtats econòmiques de la societat, ${ }^{13}$ vam copsar un procés d'empobriment de bona part de la societat selvatana: en un període marcadament inflacionista, els dots entregats es mantingueren relativament estables. Així doncs, tot semblava indicar que la majoria de les famílies selvatanes no havien pogut seguir a través dels dots l'alça dels preus, per la qual cosa el poder adquisitiu i el valor real dels dots havia minvat.

Aquesta afirmació (la de la incapacitat generalitzada de seguir l'alça dels preus) és especialment pertinent per a les classes més humils de la societat. Per a la pagesia de mas, el que observàvem era, més que no pas un empobriment generalitzat, un procés de diferenciació social on augmentaven tant els pagesos rics com els pobres. L'augment total d'efectius era certament menor en el grup dels pagesos rics que en el dels pobres, però ho era igualment en unes xifres gens menyspreables. Ara bé, en el cas de les famílies pertanyents al collectiu dels treballadors de la terra, el procés d'empobriment (o, en tot cas, d'incapacitat de millorar els dots entregats a les seves filles) era generalitzat i homogeni, fins al punt que pràcticament desapareixien les famílies treballadores que podríem considerar classes mitjanes. Esperem, doncs, que l'estudi de cas que exposem a continuació contribueixi, modestament, a comprendre una mica millor el nivell de vida (i les pautes de consum) dels grups socials subalterns rurals de l'era preindustrial.

\section{Els inventaris post mortem i l'estudi dels grups més humils: la pertinència de la font $i$ els seus biaixos}

Sempre que els historiadors treballem amb fonts notarials, ho fem assumint un cert biaix de classe: ningú no és massa ric per anar al notari, però sí que hi ha qui és massa pobre per poder-se permetre pagar els honoraris dels professionals de la fe pública. Així doncs, quan recorrem a l'estudi d'escriptures notarials amb l'objectiu d'estudiar el conjunt de la societat, som conscients que una (esperem que petita) part d'aquesta no la trobarem representada. Ara bé, hi ha algunes fonts més homogènies que d'altres i, per tant, més o menys representatives de la totalitat de la població. Durant molt temps s'havia considerat que els inventaris post mortem presentaven un marcat biaix de classe i tendien a infrarepresentar els collectius més humils. Precisament d'aquest fet neixen bona part de les crítiques a les hipòtesis que a partir de l'estudi dels inventaris pretenen inferir una revolució industriosa i consumista de les classes populars i treballadores. ${ }^{14}$ Recentment, però, alguns estudis apunten la línia que precisament a Catalunya aquest biaix socioeconòmic no era tan marcat. Així ho detecten Belén Moreno per al Penedès i especialment Rosa Congost i Rosa Ros per a les terres gironines, observant estratègies ben enginyoses com les que duien a terme moltes vídues de treballadors empordanesos, consistents a acudir al notari amb l'inventari ja redactat per tal d'estalviar-se els honoraris de fer desplaçar aquest funcionari fins a la llar del difunt. En vista d'aquestes investigacions, les possibilitats de les per-

13. Congost (2010: 161-194).

14. Yun (1999: 32-36) i Torras (2010: 181-183). 
sones amb poc o gens patrimoni de deixar un inventari continuarien essent baixes en comparació amb les d'altres collectius socioprofessionals més benestants, però en un grau molt inferior al que es detecta per a altres regions i territoris. ${ }^{15}$

Major consens historiogràfic generen en aquest sentit els capítols matrimonials, especialment a Catalunya, on la transmissió del patrimoni es fa en el moment del matrimoni de l'hereu, i no en el de la defunció del cap de família. És per això que el caràcter gairebé universal dels capítols matrimonials durant bona part de l'època moderna i les primeres dècades de la contemporània no es posa en dubte. ${ }^{16}$ Considerant, doncs, els contractes matrimonials com un retrat prou vàlid de l'estructura socioprofessional del conjunt de la població, la seva comparació amb els oficis dels difunts dels quals es redactà un inventari post mortem ens pot aportar alguna pista de la seva validesa o no com a font.

Tal com es pot apreciar al quadre 1, els inventaris de treballadors al llarg de la segona meitat del segle xviI no només presenten, quantitativament, una trajectòria ascendent, sinó que aquesta és superior a la proporció de pares de nuvi i de núvia treballadors dels capítols matrimonials de la mateixa època (amb l'única excepció dels pares de nuvi del període 1800-1805). Pitjor representats, en comparació amb els dels capítols, estarien els membres de l'altre collectiu professional vinculat al treball de la terra, els pagesos, que en els capítols matrimonials solen ser vora la meitat dels pares de núvia i, en canvi, no signifiquen ni un terç en els inventaris. Aquest fet, que podria resultar sorprenent perquè en principi els pagesos haurien de tenir major patrimoni que els treballadors (i, per tant, major interès i major capacitat econòmica per redactar un inventari), també es detecta per al conjunt de la regió de Girona amb un pic màxim en els anys 1769-1774, en què la probabilitat dels treballadors de deixar un inventari era un 64\% superior a la dels pagesos. ${ }^{17}$

Per tot el que hem anat exposant i amb totes les cauteles i prevencions necessàries, creiem detectar en la nostra mostra el patró de representativitat comú dels inventaris catalans $\mathrm{i}$, per tant, ens atrevim a donar per bona la seva pertinència i validesa a l'hora d'estudiar el comportament i les pautes de consum dels treballadors i treballadores de la terra. Tot seguit, doncs, passarem a analitzar la informació i les dades que ens aporten els prop d'un centenar d'inventaris de treballadors selvatans que hem recopilat, buidat i analitzat per als tres períodes cronològics esmentats a dalt, a saber: 1750-1755, 1775-1780 i 1800-1805.

15. Per al cas penedesenc, vegeu Moreno (2018: 45-48), i per a la regió de Girona, Congost i Ros (2018: 65-75).

16. Ros (2010: 11). Sobre l'inici de l'erosió en la pràctica de redactar capítols matrimonials, vegeu els capítols d'aquest mateix llibre de Julie Marfany (2010:105-114) i Rosa Ros (2010: 115-134). En relació amb el seu declivi final i en aquesta mateixa obra, vegeu Congost (2010: 89-104).

17. Congost i Ros (2018: 72). 


\section{Quadre 1 \\ Comparació entre l'estructura socioprofessional dels difunts amb inventari post mortem i dels pares de núvia i de nuvi dels capítols matrimonials per als mateixos talls cronològics i la mateixa àrea geogràfica (notaries selvatanes)}

\begin{tabular}{|c|c|c|c|c|c|c|c|c|c|}
\hline & \multicolumn{3}{|c|}{$1750-1755$} & \multicolumn{3}{|c|}{$1775-1780$} & \multicolumn{3}{|c|}{$1800-1805$} \\
\hline & \multirow{2}{*}{\begin{tabular}{|c|}
$\begin{array}{c}\text { Inventaris } \\
(n=108)\end{array}$ \\
Difunt
\end{tabular}} & \multicolumn{2}{|c|}{$\begin{array}{c}\text { Capítols matr. } \\
(n=306)\end{array}$} & \multirow{2}{*}{\begin{tabular}{|c|}
$\begin{array}{c}\text { Inventaris } \\
(n=104)\end{array}$ \\
Difunt
\end{tabular}} & \multicolumn{2}{|c|}{$\begin{array}{c}\text { Capítols matr. } \\
(n=265)\end{array}$} & \multirow{2}{*}{\begin{tabular}{|c|}
$\begin{array}{c}\text { Inventaris } \\
(n=94)\end{array}$ \\
Difunt
\end{tabular}} & \multicolumn{2}{|c|}{$\begin{array}{c}\text { Capítols matr } \\
\quad(n=248)\end{array}$} \\
\hline & & $\begin{array}{c}\text { Pare } \\
\text { núvia }\end{array}$ & $\begin{array}{l}\text { Pare } \\
\text { nuvi }\end{array}$ & & $\begin{array}{l}\text { Pare } \\
\text { núvia }\end{array}$ & $\begin{array}{l}\text { Pare } \\
\text { nuvi }\end{array}$ & & $\begin{array}{l}\text { Pare } \\
\text { núvia }\end{array}$ & $\begin{array}{l}\text { Pare } \\
\text { nuvi }\end{array}$ \\
\hline Pagesos & $29,6 \%$ & $55,3 \%$ & $50,8 \%$ & $36,5 \%$ & $45,4 \%$ & $34,5 \%$ & $30,9 \%$ & $54,3 \%$ & $40 \%$ \\
\hline Treballadors & $25,9 \%$ & $20,9 \%$ & $23,4 \%$ & $33,7 \%$ & $23,7 \%$ & $30,7 \%$ & $29,8 \%$ & $23,4 \%$ & $35,9 \%$ \\
\hline Artesans & $27,8 \%$ & $15,9 \%$ & $20,5 \%$ & $15,4 \%$ & $18,3 \%$ & $22,7 \%$ & $20,2 \%$ & $13,3 \%$ & $15,5 \%$ \\
\hline Comerciants & $7,4 \%$ & $5,3 \%$ & $4 \%$ & $3,8 \%$ & $4,6 \%$ & $4,5 \%$ & $5,3 \%$ & $6,4 \%$ & $7,3 \%$ \\
\hline $\begin{array}{l}\text { Professionals } \\
\text { lliberals }\end{array}$ & $6,5 \%$ & $1,7 \%$ & $0,7 \%$ & $2,9 \%$ & $3,8 \%$ & $2,3 \%$ & $2,1 \%$ & $2,2 \%$ & $0 \%$ \\
\hline Altres & $2,8 \%$ & $1 \%$ & $0,7 \%$ & $7,7 \%$ & $4,2 \%$ & $5,3 \%$ & $11,7 \%$ & $0,5 \%$ & $1,2 \%$ \\
\hline
\end{tabular}

\section{Les cases dels treballadors: per dins i per fora}

El 3 d'abril de 1764 el mestre de cases Joan Maldonado i el fuster Isidro Turon feren una àpoca d'obres a favor de Joan Bayer, treballador de la terra de Brunyola, per «fer y obrar aquella caseta que vos, dit Joan Bayer, haveu feta construhir en aquella pessa de terra que teniu y possehiu sita en dita parroquia de Brunyola que son de pertinencias del Mas Turon». Sense entrar ara a analitzar el complex i enrevessat sistema a l'entorn de la propietat de la terra en les societats de l'època, ${ }^{18}$ val la pena destacar que en Joan Bayer posseïa una peça de terra, al mateix temps que aquesta pertanyia a un mas (per tant i segurament, a un pagès propietari). En tot cas, el que ens interessa ara és veure com aquest treballador brunyolenc es feu edificar, no pas una casa, sinó una caseta (res no és gratuït davant del notari; l'ús de diminutius, tampoc), en un sòl sobre el qual tenia algun dret de propietat. Si hem de jutjar pel memorial de les obres, la casa s'aixecava sobre 750 teules i 100 rajols. El sostre s'aguantava gràcies a 19 «cayrats» (o sigui, bigues) ajudats per «quatre dotsenas de llates» (les peces de fusta més estretes que, collocades perpendicularment a les bigues, sostenen les teules del sostre). Tenia una única porta i aparentment cap finestra. Tot plegat costà a Joan Bayer un total de 56 lliures barcelonines, 10 sous i 6 diners. El mestre de cases hi dedica 23 jornals propis i 46 jornals de manobre. El fuster anava a preu fet

18. En relació amb aquesta matèria, vegeu Congost (2007b), que presenta una revisió crítica sobre com s'ha interpretat historiogràficament l'evolució de les formes de propietat de la terra en el trànsit entre aquelles dues societats que hem batejat com a «antic règim» $\mathrm{i}$ la sorgida de la «revolució liberal». 
i no especifica quants jornals hi va treballar. En tot cas, podem imaginar que per edificar aquesta modesta caseta hi treballaren durant 23 dies el mestre de cases i un parell de manobres, juntament amb el fuster. 16 dels jornals de manobre es van pagar a 6 sous cadascun (0,3 lliures) i els 30 restants, a 7 sous (0,35 lliures). A Joan Bayer, doncs, fer-se edificar una llar li va costar entre 161 i 188 jornals de manobre, o sigui, de treballador no qualificat.

Tres anys abans, Joan Colomer, treballador del veïnat de les Mallorquines, a la parròquia de Sils, realitzà unes obres de millora a la seva nova llar, en la qual havia entrat en casar-se amb Margarida Barris, vídua del també treballador Joseph Brun. Les obres esmentades li costaren 136 lliures, 9 sous i 6 diners, tal com consta en l'àpoca d'obres que redactaren a favor seu Jaume Duch, mestre de cases, i Matheu Font, fuster. Per tant, aquestes obres de millora (en principi, reformar hauria de ser més senzill que construir una casa sencera) li costaren gairebé el triple del que hagué d'invertir Joan Bayer en la construcció de la seva llar. La descripció de les tasques que s'hi realitzaren ens evoca una estructura de casa força més complexa que la de l'exemple anterior. S'hi va «fer la ximenea y dos finestrons», també es van «posar la ayguera, los fogons» $\mathrm{i}$ «lo forn a la cuyna nova». Finalment, van fer també una «escala y un enva de rajola sobre la cuyna» i van «rebatrer la cambra de sobra la entrada». La casa tenia, per tant, dos pisos i com a mínim tres estances: entrada i cuina a la planta baixa i un dormitori al pis superior.

Com eren, doncs, les cases dels treballadors selvatans de mitjan segle xviII? La caseta que es feu construir Joan Bayer responia a la tònica general de llar treballadora de l'època? O més aviat hem de pensar en estructures habitacionals més grans i complexes, com la del matrimoni Colomer-Barris? De moment encara no analitzarem el règim de tinença de la llar i les terres (ho abordarem més endavant), sinó que en el quadre 2 mostrem únicament com s'anomenava en l'inventari el lloc de residència dels difunts treballadors que componen la nostra mostra (en els casos on s'indicava, que per sort són la majoria).

Al llarg dels tres talls cronològics estudiats s'aprecia una clara millora de la tipologia d'habitatge on residien els treballadors. Per al primer període, vora 8 de cada 10 llars treballadores estaven formades únicament per la casa en si. Una mica menys del 10\% dels treballadors tenien un hort contigu a la casa. Finalment, un 10\% dels inventaris descrivien alguna estructura inferior a la d'una casa: caseta, barraca, tros o estança de casa, etc. Al llarg dels dos períodes següents la situació varia força: primer augmenten significativament les llars treballadores formades per casa i hort; després augmenten les cases amb unitats de terra superiors a l'hort (eres, feixes, peces de terra), de tal manera que en el període 1800-1805 menys de la meitat dels inventaris de treballadors esmenten només una «casa» i, en canvi, els conjunts «casa + hort» $\mathrm{i}$ «casa + terres» representen cadascun d'ells una quarta part de la mostra analitzada. 


\section{Quadre 2}

Tipus d'habitatge on residien els treballadors

\begin{tabular}{|l|c|c|c|}
\hline & $\begin{array}{c}\mathbf{1 7 5 0 - 1 7 5 5} \\
(\boldsymbol{n}=\mathbf{2 1})\end{array}$ & $\begin{array}{c}\mathbf{1 7 7 5 - 1 7 8 0} \\
(\boldsymbol{n}=\mathbf{2 6})\end{array}$ & $\begin{array}{c}\mathbf{1 8 0 0 - 1 8 0 5} \\
(\boldsymbol{n}=\mathbf{2 4})\end{array}$ \\
\hline Casa & $81,0 \%$ & $50,0 \%$ & $45,8 \%$ \\
\hline Casa amb hort & $9,5 \%$ & $30,8 \%$ & $25,0 \%$ \\
\hline Casa amb terres & $0,0 \%$ & $7,7 \%$ & $25,0 \%$ \\
\hline Caseta, barraca o part de casa & $9,5 \%$ & $11,5 \%$ & $4,2 \%$ \\
\hline
\end{tabular}

De fet, en el darrer dels períodes estudiats, si hom examina els inventaris amb deteniment, el que es pot observar és una notable diferenciació en el tipus de llar on habitaven els treballadors. En un extrem, per exemple, hi tindríem el quasi pagès Aciscle Vicens. No és que nosaltres el considerem com a gairebé membre de la pagesia, sinó que en aquest inventari, redactat a la notaria de Caldes de Malavella el 21 d'abril de 1805, l'etiqueten com a «pages o menestral», i tot fa pensar que si no el podien considerar pròpiament un pagès era únicament perquè no vivia en un mas (allò que a la regió de Girona i en general a la Catalunya Vella diferencia la pagesia de la resta). Residia en una casa «vulgarment anomenada casa Manuel», però que es descriu utilitzant la fórmula i la retòrica notarial que se solien reservar per a la descripció de masos: «casa junt ab sas terras honors y possessions». En l'altre extrem podríem esmentar casos com el del roder hilarienc Gaspar Crous. El 19 de desembre de 1800 la seva vídua, Margarida Tosell, redacta l'inventari de béns del seu difunt marit, amb el qual residia al carrer «dit de las tres creus» en una «estancia de la part de la casa y hort de Ferriol Fabrega, teixidor de lli». Més endavant especifica que l'havia adquirida (la «part de casa» esmentada) «lo dit mon marit a carta de gracia».

El cas de Gaspar Crous no és, però, l'únic cas de residència en estructures inferiors a la d'una casa completa. Tenim també, per exemple, el cas del bracer arbucienc Thomas Mas, que vivia en una «estancia o part de casa» juntament amb «aquelles feixes de terra que dit mon marit possehia a carta de gracia»; o el del bracer de Riells del Montseny Magí Clos, que vivia en una «caseta y terres anomenades del Minyo». El mateix diminutiu s'utilitza per definir l'habitatge de Pere Prats, ${ }^{19} \mathrm{i}$ aparentment és millor que el del treballador Dalmau Roure, que vivia en una «barraca».

Amb hort o sense, amb terres o sense, més grosses o més petites, com era l'estructura de les llars dels treballadors? És a dir, quines i quantes estances tenien les seves cases? De nou, l'anàlisi comparativa dels tres períodes estudiats ens mostra diferències notables. Hem de dir, d'entrada, que en alguns casos l'inventari no anomena les diferents habita-

19. Tot i viure en una "caseta», tenia en propietat 6 vessanes de terra (vora 1,5 hectàrees), amb una part sembrada de forment, una part plantada de vinya i diversos arbres fruiters, i una darrera part boscosa. Una extensió de terra gens menyspreable en el context dels treballadors selvatans de l'època, tal com veurem més endavant. 
cions. No es pot descartar, especialment en els inventaris més modestos, que la casa estigués formada per una sola estança. En altres casos, per l'ordre en com estan descrits els diferents béns mobles, resultaria relativament senzill deduir quan es passava d'una habitació a l'altra. Quan s'especifica clarament que la casa era en propietat, gairebé sempre s'hi identifiquen les estances. Quan no s'indica el règim de tinença (o quan aquest era l'arrendament), és quan solem trobar els inventaris sense identificar-les. Quelcom semblant passa quan estudiem el collectiu dels pagesos, en què en alguns inventaris de masovers no s'especifiquen les diferents estances. Per més modest que fos el mas que menaven, resulta complicat pensar que no tingués més d'una cambra. Tot plegat ens porta a pensar que quan l'habitatge és en propietat, l'inventari descriu tot el que hi ha a la casa, i això inclou també les diferents habitacions. En canvi, quan s'hi residia en algun altre règim de tinença (normalment, l'arrendament), l'inventari es limita a descriure els béns, com si les parets que separaven una habitació de l'altra no fossin del difunt (que, de fet i en una interpretació estricta dels drets de propietat, no ho eren).

Hi ha, en tot cas, alguns inventaris en els quals sí que tot sembla indicar que realment la casa estava constituïda per una sola estança. El 29 de juny de 1753 els marmessors del testament de Valentí Triquer (i tutors dels seus fills impúbers) redacten l'inventari post mortem d'aquest treballador d'Amer que residia al carrer del «Pedraguet» d'aquesta vila. L'inventari comença situant-se «en la entrada de dita casa». Els primers béns enumerats, però, són els habituals en una cuina: una perola d'aram, uns clemàstecs, la pala del foc, etc. Tot seguit es mencionen un petit grup d'estris per treballar la terra: un parell d'aixades, un aixadell, una fanga, un magall i una destral (en tots s'especifica que el seu estat de conservació és dolent). A continuació i finalment, es pren nota de la presència de dues màrfegues (també dolentes) i una flassada de llana. Val a dir que en aquest cas l'extrema modèstia de la casa no significa que Triquer fos un treballador especialment pobre. La casa era propietat seva i posseïa també tres vessanes de vinya, d'on també havia obtingut «sinch gavallons de forment prossehits en la present collita de dita vinya» $\mathrm{i}$ «set miyoyas de favas tambe prossehidas de la present collita de dita vinya». Com veurem més endavant, no tots els treballadors de mitjan segle xviI tenien la casa en propietat, i encara menys tenien peces de terra en propietat. A més, Triquer tenia quatre tovallons de borràs, en un període en què només se'n trobaven al 32\% de les llars treballadores. ${ }^{20}$

Un cas molt semblant seria el del treballador de Santa Coloma de Farners anomenat Tomàs Riera. També residia en una casa propietat seva (situada «al carrer de dalt»). Així mateix, també era propietari de dos horts i tres vessanes de terra cultiva on hi havia vinya i altres arbres fruiters. L'inventari de la casa, redactat el 29 de març de 1779, sembla començar i acabar en l'única estança de la casa, que etiqueten com a «cuina». L'estructura del llistat de béns és idèntica a la del llistat de Valentí Triquer: comença amb alguns estris bàsics de cuina, segueix amb algunes eines de treball, en aquest cas dues aixades, una destral i una falç de segar (juntament amb un «estellador de ferro de estallar

20. Vegeu el quadre 5, p. 83. 
piñas»), ${ }^{21}$ i finalment esmenta uns bancs de llit amb una màrfega i dos llençols de bri i borràs.

No podem, doncs, inferir una relació directa entre la mida i l'estructura de les cases, i el nivell de riquesa dels treballadors. Es podia residir en una llar d'allò més simple i modesta, al mateix temps que posseïes vora una hectàrea de terra, en una època en què gairebé en una cinquena part dels inventaris de treballadors no hi havia cap tipus de terra en propietat (gràfics 1 i 2). En tot cas, sí que volem fer notar que, tal com s'aprecia al quadre 3, al llarg dels tres períodes analitzats l'estructura de les cases dels treballadors selvatans anà millorant. Partim d'una mitjana de 3,9 estances a les llars dels inventaris dels anys 1750-1755, que passa a 5,4 en els inventaris redactats als primers anys del segle xIx. Al Baix Empordà i per al mateix període cronològic, les cases dels treballadors (que pagaven i rebien, gairebé sempre, dots molt més elevats que els dels selvatans) ${ }^{22}$ passaren de 3,5 estances a 4,2.23 Aquesta crescuda és deguda en part a l'augment de cambres destinades a l'emmagatzematge, com graners, rebosts o terrats. D'altra banda, també es deu a l'augment del nombre de dormitoris. Si a mitjan segle xviI només el 3,6\% dels inventaris de treballadors tenien dos o més dormitoris, un quart de segle després la xifra havia augmentat fins al 45,7\%, si bé va baixar lleugerament fins al 46,4\% en els inventaris del període 18001805 .

Quadre 3

Mitjana d'estances per domicili i percentatge de cada tipus

\begin{tabular}{|l|c|c|c|}
\hline & $\begin{array}{c}\mathbf{1 7 5 0 - 1 7 5 5} \\
(\boldsymbol{n}=\mathbf{2 8})\end{array}$ & $\begin{array}{c}\mathbf{1 7 7 5 - 1 7 8 0} \\
(\boldsymbol{n}=\mathbf{3 5})\end{array}$ & $\begin{array}{c}\mathbf{1 8 0 0 - 1 8 0 5} \\
(\boldsymbol{n}=\mathbf{2 8})\end{array}$ \\
\hline Mitjana d'estances & 3,9 & 4,4 & 5,4 \\
\hline Entrada & $46,4 \%$ & $42,9 \%$ & $32,1 \%$ \\
\hline Cuina & $64,3 \%$ & $77,1 \%$ & $57,1 \%$ \\
\hline Sala & $14,3 \%$ & $22,9 \%$ & $17,9 \%$ \\
\hline Menjador & $0,0 \%$ & $0,0 \%$ & $3,6 \%$ \\
\hline Dormitori 1 & $53,6 \%$ & $60,0 \%$ & $46,4 \%$ \\
\hline Dormitori 2 & $3,6 \%$ & $31,4 \%$ & $28,6 \%$ \\
\hline
\end{tabular}

21. Fem èmfasi en aquest curiós estri perquè en una zona de pinedes abundants podria ser una mostra de la moltes vegades invisible i difícil de detectar existència de pluriactivitats que servien per complementar els ingressos de la unitat familiar. A més i si hem de jutjar pel que explicava el viatger Francisco de Zamora quan va passar per Santa Coloma de Farners a finals del segle xviI, sembla que les dones solien fer la feina d'estellar les pinyes per extreure'n els pinyons i tenia com a destí la seva comercialització i exportació: «En este pueblo se cogen bastantes piñones y, además, los hombres se dedican a coger las piñas de los términos inmediatos, quebrándolos después las mujeres uno a uno, con lo cual salen más de enteros». Així mateix i en referència al mercat setmanal que se celebrava els dilluns, destacava que «se vende mucho piñon [...] para Mahón, Valéncia, Cartagena, Cádiz y otras partes» (Zamora 1973: 303).

22. Mas (2016b: 78) i Esteve (2011: 278).

23. Càlcul propi a partir d'Esteve (2011: 85 i 114). 


\begin{tabular}{|l|c|c|c|}
\hline Dormitori 3 & $0,0 \%$ & $8,6 \%$ & $21,4 \%$ \\
\hline Dormitori 4 & $0,0 \%$ & $5,7 \%$ & $0,0 \%$ \\
\hline Celler & $28,6 \%$ & $31,4 \%$ & $25,0 \%$ \\
\hline Cort & $25,0 \%$ & $37,1 \%$ & $35,7 \%$ \\
\hline Graner & $0,0 \%$ & $2,9 \%$ & $10,7 \%$ \\
\hline Rebost & $0,0 \%$ & $0,0 \%$ & $7,1 \%$ \\
\hline Pallissa & $7,1 \%$ & $2,9 \%$ & $3,6 \%$ \\
\hline Terrat & $3,6 \%$ & $11,4 \%$ & $14,3 \%$ \\
\hline Golfa / sostre & $0,0 \%$ & $8,6 \%$ & $0,0 \%$ \\
\hline Eixida & $3,6 \%$ & $0,0 \%$ & $3,6 \%$ \\
\hline Porxo & $0,0 \%$ & $0,0 \%$ & $7,1 \%$ \\
\hline Pati & $0,0 \%$ & $0,0 \%$ & $7,1 \%$ \\
\hline
\end{tabular}

Arribats a aquest punt, voldríem fer notar que moltes vegades les xifres mitjanes i els percentatges poden ocultar dinàmiques oposades molt rellevants i significatives. Si mirem amb deteniment els percentatges de dormitoris que constaven en els inventaris dels anys 1800-1805, es pot observar que és el període cronològic en què trobem simultàniament menys inventaris amb, com a mínim, un dormitori $(46,4 \%)$ i, en canvi, hi trobem la xifra més alta d'habitatges amb tres o més dormitoris (21,4\%). Dit d'una altra manera, en els inventaris de principis del segle xIX s'observa una marcada diferenciació entre les llars de treballadors que no tenien cap estança destinada a dormitori i les que en canvi en tenien més de dues. A parer nostre, aquesta constatació resulta d'allò més rellevant, ja que en estudiar el moviment dels dots ja vam detectar un notable procés de diferenciació social en el si de la pagesia de mas, però, en canvi, per als treballadors de la terra el que vam observar era un empobriment generalitzat. Altrament i si hem de jutjar per l'estructura de les cases, sí que observem una polarització en el si d'aquest collectiu. Més endavant recuperarem aquest fil amb l'estudi de les pautes de consum i el rol dels treballadors econòmicament més reeixits (els menestrals). De moment ens limitarem a fer notar aquesta diferència en l'estructura de les diferents cases.

Si analitzem ara la relació d'aquests treballadors amb la propietat de la terra (gràfic 1), apreciarem un fenomen curiós i visualment molt clar: al llarg de la segona meitat del segle xviI es produeix una petita reducció del nombre de treballadors que tenien casa en propietat i un augment, també modest però en un ordre de magnitud superior, dels que tenien terres en propietat. Concretament, del 75\% de treballadors propietaris de la llar on residien segons els inventaris dels anys 1750-1755, passem a un 68\% a principis del segle xix. Per altra part, els treballadors que són propietaris d'alguna peça de terra (per petita que sigui) presenten una tendència alcista i són gairebé un 80\% els anys 1800-1805, mentre que mig segle endarrere només el 64\% dels treballadors tenien terra. De nou (i com apuntem des de l'inici del treball), a principis del segle xix s'observa un procés de diferenciació i polarització en el si dels treballadors. Es tracta simultàniament del període en 
què hi ha més treballadors que gaudeixen tant de casa com de terra en propietat (68\%) i el període en què hi ha més treballadors que no tenen cap de les dues coses $(21,4 \%)$.

Tot plegat són canvis percentuals petits, que en una mostra d'inventaris igualment petita han de ser interpretats amb molta cautela, ja que podrien ser deguts a factors atzarosos en la composició de la mostra. Ara bé, considerem que la suma de tots ells representa un indici prou sòlid per plantejar-nos la hipòtesi (que ha aparegut $\mathrm{i}$ anirà apareixent $\mathrm{al}$ llarg de tot el present treball) de si estem efectivament assistint a la gènesi d'un procés de diferenciació en el si dels treballadors de la terra, que hauria conduït a la llarga fins i tot al naixement i l'adopció d'una nova etiqueta socioprofessional. ${ }^{24}$

Pel que fa a l'extensió de les peces de terra que posseïen (gràfic 2), també presenta un comportament positiu. Si a mitjan segle xvil no teníem cap inventari d'un treballador que tingués 3 ha o més de terreny en propietat, als anys 1775-1780 ja en trobem un 8,6\%, al mateix temps que gairebé la meitat dels treballadors (48,6\%) són tenidors d'entre 1 i 1,99 ha. El nombre dels que posseeixen menys d' 1 ha es manté estable en vora el $25 \%$ al llarg dels dos períodes. De nou i pel que fa als inventaris del període 1800-1805, constatem una bifurcació de les trajectòries: disminueixen considerablement els que tenen entre 1 i 2,99 ha i augmenten els que tenen menys d' 1 ha, que passen del 25,7\% al 39,3\%. Parallelament, la proporció dels que tenen 3 ha o més de terra en propietat es manté estable, si bé ja localitzem per primera vegada algun treballadors que té més de 5 ha de terra pròpia.

Podem comparar aquestes xifres amb les del conjunt de la regió de Girona contingudes en el mencionat treball de Rosa Congost i Rosa $\operatorname{Ros}^{25} \mathrm{i}$ observarem que, més enllà de les particularitats evolutives que hem anat esmentant, sempre i al llarg de tota la segona meitat del segle xvir els treballadors selvatans presenten xifres inferiors d'accés a la propietat de la terra, i els que en tenen, són possessions d'extensió més reduïda. L'evolució del percentatge de treballadors sense terra presenta un comportament similar: el pic més baix és en els inventaris dels anys setanta del segle xviII, i en el conjunt dels cinquanta anys estudiats la reducció és aproximadament d'un $50 \%$. Ara bé, en el conjunt de la regió gironina partien d'un $22,2 \%$, que es reduïa fins a un $10,3 \%$, i en el nostre treball partíem d'un $35,7 \%$, que cau fins a un 17,9\%. Les majors diferències són entre els treballadors que posseeixen més de 3 ha. En el primer període analitzat, la proporció de treballadors gironins amb terres d'aquesta extensió era de gairebé un 10\%. Vint anys més tard supera el 20\%, un 3,1\% del qual és la proporció de treballadors que ja tenien més de 5 ha. A la mateixa època, en els inventaris de treballadors selvatans només un 8,6\% tenen entre 3 i 4,99 ha. Situats a la primeria del segle xix, en l'estudi de Congost i Ros la xifra ha augmentat fins a gairebé un 25\% (amb un 12,1\% que posseeixen ja més de 5 ha). En el nostre cas, la xifra se situa en un $7,2 \%$. En definitiva, són tendències evolutivament similars (tant pels que no tenen terra com per l'extensió dels que sí que en tenen), però partint i acabant amb xifres inferiors en el nostre cas.

24. Vegeu la reflexió final que ferm sobre aquesta qüestió a les p. 89-92.

25. Vegeu el quadre 7 (2011: 84). 


\section{Gràfic 1}

Evolució del percentatge de treballadors propietaris de casa i/o de terres segons el que consta en el seu inventari

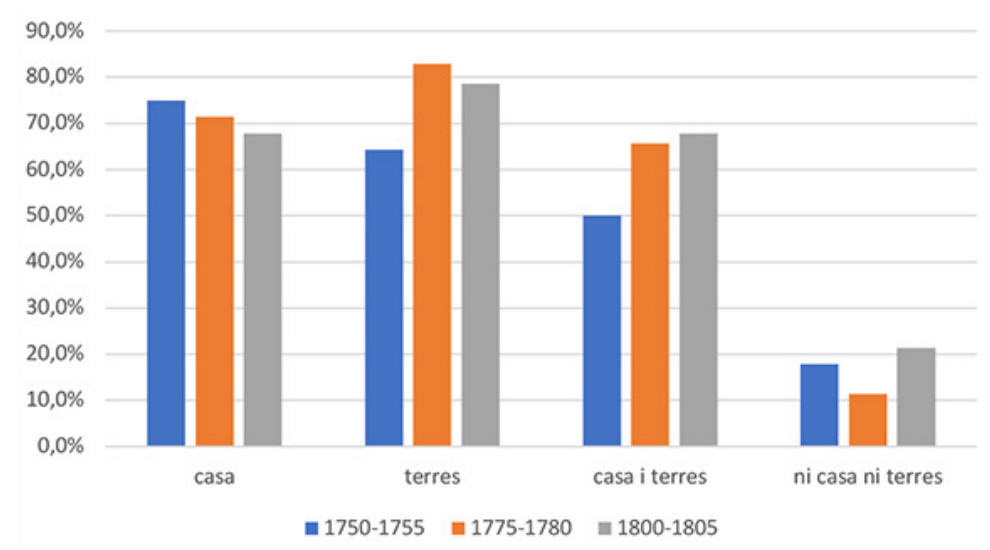

Gràfic 2

Distribució de la propietat de la terra en funció de la seva extensió total (en hectàrees [ha])

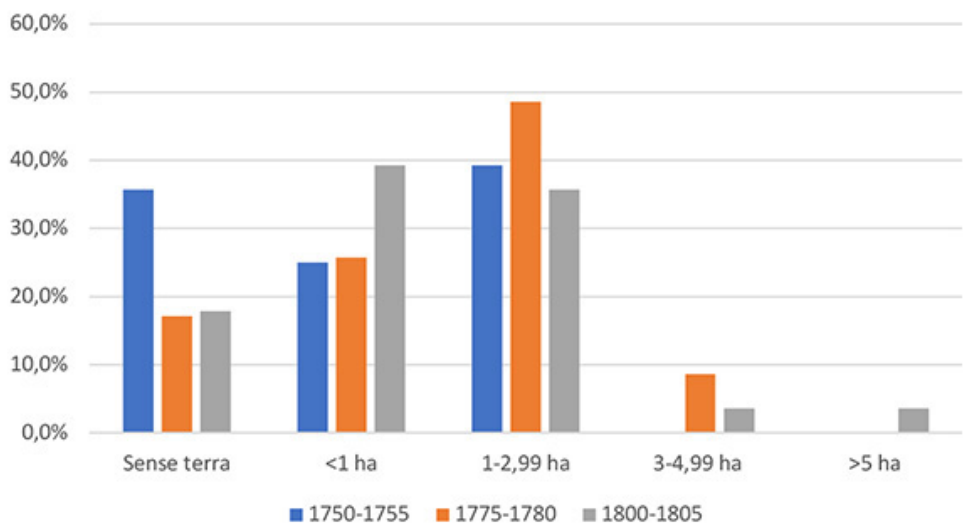




\section{Quadre 4}

\section{Comparativa de l'extensió de terra posseïda pels treballadors selvatans amb el conjunt de la regió de Girona}

\begin{tabular}{|l|c|c|c|c|c|c|}
\hline & $\begin{array}{c}\text { Girona } \\
\mathbf{1 7 5 0 - 1 7 5 5} \\
(\boldsymbol{n}=\mathbf{4 9})\end{array}$ & $\begin{array}{c}\text { La Selva } \\
\mathbf{1 7 5 0 - 1 7 5 5} \\
(\boldsymbol{n}=\mathbf{2 8})\end{array}$ & $\begin{array}{c}\text { Girona } \\
\mathbf{1 7 6 9 - 1 7 7 4} \\
(\boldsymbol{n}=\mathbf{1 2 2})\end{array}$ & $\begin{array}{c}\text { La Selva } \\
\mathbf{1 7 7 5 - 1 7 8 0} \\
(\boldsymbol{n}=\mathbf{3 5})\end{array}$ & $\begin{array}{c}\text { Girona } \\
\mathbf{1 8 0 0 - 1 8 0 5} \\
(\boldsymbol{n}=\mathbf{5 8})\end{array}$ & $\begin{array}{c}\text { La Selva } \\
\mathbf{1 8 0 0 - 1 8 0 5} \\
(\boldsymbol{n}=\mathbf{2 8})\end{array}$ \\
\hline Sense terra & $22,2 \%$ & $35,7 \%$ & $8,6 \%$ & $17,1 \%$ & $10,3 \%$ & $17,9 \%$ \\
\hline$<1$ ha & $35,2 \%$ & $25 \%$ & $36,7 \%$ & $25,7 \%$ & $29,3 \%$ & $39,3 \%$ \\
\hline 1-2,99 ha & $33,3 \%$ & $39,3 \%$ & $33,6 \%$ & $48,6 \%$ & $36,2 \%$ & $35,7 \%$ \\
\hline $3-4,99$ ha & $7,4 \%$ & $0 \%$ & $18 \%$ & $8,6 \%$ & $12,1 \%$ & $3,6 \%$ \\
\hline$>5$ ha & $1,9 \%$ & $0 \%$ & $3,1 \%$ & $0 \%$ & $12,1 \%$ & $3,6 \%$ \\
\hline
\end{tabular}

Font: elaboració pròpia a partir de Congost i Ros (2018: 84).

\section{Les pautes de consum dels treballadors selvatans: alguns indicadors de consum}

Una vegada vistes les cases i les terres dels treballadors i els drets de propietat que podien o no tenir sobre aquestes, una altra informació valuosa que ens aporten els inventaris post mortem és la relativa a l'adquisició i el consum de béns mobles. Per fer-ho, hem seleccionat una sèrie d'objectes que es consideren rellevants per a l'estudi de les pautes de consum i ens hem fixat en l'evolució de dos indicadors: el percentatge d'inventaris on localitzem aquests ítems determinats i la quantitat mediana que en tenien aquestes llars. En objectes d'ús molt comú que haurien de ser presents a (quasi) totes les llars, resulta més interessant fixar-nos en l'evolució de la mediana. Pel que fa als objectes més rars o considerats de luxe o semiluxe, el que resulta rellevant és el percentatge de casos, ja que la quantitat d'aquests objectes en els casos en què en localitzem serà, habitualment, d'un. ${ }^{26}$

De l'anàlisi de les xifres que mostrem en el quadre 5 es desprenen alguns canvis interessants en les pautes de consum, tant pel que fa a la introducció d'alguns ítems com a l'augment d'altres que ja eren presents en els inventaris de 1750-1755. Lluny, però, quedaria qualsevol indici d'una febre consumista dels treballadors de la terra selvatans. Llençols i camises - que podríem dir que són els dos béns tèxtils més «universals»- presenten un augment molt lleu en la mediana (de 4 a 5 els uns i de 3 a 4 els altres). Per al mateix període i a la regió de Girona, l'augment seria de 7 a 8 i de 5 a 8 , respectivament. Pel que fa a les estovalles i els tovallons, objectes no tan comuns en les llars més humils, sí que observem un augment notable del percentatge d'inventaris que n'inclouen, però en una quantitat que es manté estable o que fins i tot es redueix lleugerament. És a dir, se'n comença a democratitzar el consum, però en quantitats molt modestes.

26. Trobem aquesta mateixa reflexió a Congost i Ros (2018: 82). 


\section{Quadre 5}

\section{Evolució de la presència d'alguns objectes en els inventaris de treballadors i quantitat mediana d'aquests}

\begin{tabular}{|l|c|c|c|c|c|c|}
\hline & \multicolumn{2}{|c|}{$\mathbf{1 7 5 0 - 1 7 5 5}$} & \multicolumn{2}{c|}{$\mathbf{1 7 7 5 - 1 7 8 0}$} & \multicolumn{2}{c|}{$\mathbf{1 8 0 0 - 1 8 0 5}$} \\
\hline & $\begin{array}{c}\text { casos } \\
(n=28)\end{array}$ & mediana & $\begin{array}{c}\text { casos } \\
(n=35)\end{array}$ & mediana & $\begin{array}{c}\text { casos } \\
(n=28)\end{array}$ & mediana \\
\hline Llençols & $67,9 \%$ & 4 & $80,0 \%$ & 4 & $96,4 \%$ & 5 \\
\hline Camises & $50,0 \%$ & 3 & $45,7 \%$ & 3 & $25,0 \%$ & 4 \\
\hline Estovalles & $57,1 \%$ & 2 & $45,7 \%$ & 2 & $64,3 \%$ & 2 \\
\hline Tovallons & $32,1 \%$ & 4 & $37,1 \%$ & 3 & $53,6 \%$ & 3 \\
\hline Culleres & $32,1 \%$ & 4 & $37,1 \%$ & 6 & $71,4 \%$ & 10 \\
\hline Forquilles & $0,0 \%$ & 0 & $20,0 \%$ & 3 & $53,6 \%$ & 5 \\
\hline Xocolateres & $0,0 \%$ & 0 & $0,0 \%$ & 0 & $7,1 \%$ & 1 \\
\hline Bestiar de treball & $35,7 \%$ & 1 & $31,4 \%$ & 1 & $28,6 \%$ & 1 \\
\hline
\end{tabular}

L'augment més significatiu és en les culleres, que si a mitjan segle xviI vora un terç de les llars treballadores en tenien (amb una quantitat mediana de 4), a principis del xix en trobem al 71,4\% de les llars i amb una mediana de 10. Això es complementa, a més, amb l'arribada de les forquilles, el nombre de les quals va creixent gradualment: de no trobar-ne cap als inventaris del període 1750-1755, passem a un 20\% en els de 1775-1780 i, finalment, a haver-n'hi a principis del segle xix al 53,6\% de les llars estudiades i una quantitat mediana de 5. I s'arrodoneix, a més, tal com s'aprecia al gràfic 3 , amb la quasi desaparició de les culleres i forquilles de fusta, que passen a ser gairebé en exclusiva fetes d'un material menys perible, més resistent a la humitat i ignífug: el llautó.

Aquest augment, considerable i progressiu, de la presència de culleres en els inventaris al llarg de la segona meitat del segle xvin coincideix amb la cronologia que també detecta Jaume Codina per a l'àrea del delta del Llobregat i que batejà com la «revolució de les culleres». ${ }^{27}$ L'autor situa l'arrencada «revolucionària» vers l'any 1745 , en detectar-ne en un terç dels inventaris, igualment que en el cas dels treballadors selvatans, ja que en localitzem en el 32,1\% de les llars. De llavors ençà, la xifra ha anat augmentant. Així mateix, també detecta parallelament la substitució de les de fusta per les de llautó.

Tota possible eufòria queda esmorteïda en constatar que en els mateixos primers sis anys del segle xix al conjunt de la regió de Girona tenien culleres i forquilles el $88 \%$ de les

27. En el seu treball sobre els orígens del creixement modern de la població, l'autor relaciona la generalització de l'ús de culleres amb millores en la higiene i la salubritat que haurien facilitat la desempallegada demogràfica que es produí en aquella època: «la revolució de les culleres, aparellada i de bracet amb la revolució demogràfica; aquesta, conseqüència -almenys en part- d'aquella en rebre l'infantó l'aliment des d'un tros de fusta o de metall en comptes, tot sovint, directament d'unes mans amorosívoles però contaminades» (Codina 1998: 52). 
llars treballadores amb una mediana de 12 i 9, respectivament. D'altra banda, ja es localitzaven forquilles als anys vint $i$ trenta del segle xviI, mentre que en el nostre estudi hem d'esperar fins al darrer terç de segle per començar a detectar-ne.

Quelcom similar succeeix amb un objecte encara més rar de localitzar en les llars humils (i no tan humils) i considerat, ara sí, un autèntic indicador d'estatus social i de consum d'un producte colonial: les xocolateres. Hem d'esperar fins al darrer dels tres períodes analitzats per localitzar les primeres xocolateres entre els inventaris de treballadors selvatans. En altres indrets de la regió de Girona se'n comencen a localitzar a partir dels anys setanta del segle xviII, i a principis del xIx ja se'n detecten al $41 \%$ dels inventaris. Més similars als nostres resultats són els que detecta Albert Serramontmany per a l'àrea de Besalú, on tampoc no se'n troben fins a principis del segle xix i, encara, només en el 8\% dels inventaris de treballador ${ }^{28}$ (en el nostre treball el percentatge de xocolateres és del $7,1 \%)$.

\section{Gràfic 3 \\ Evolució del material amb què s'elaboraven les culleres i forquilles localitzades en els inventaris}

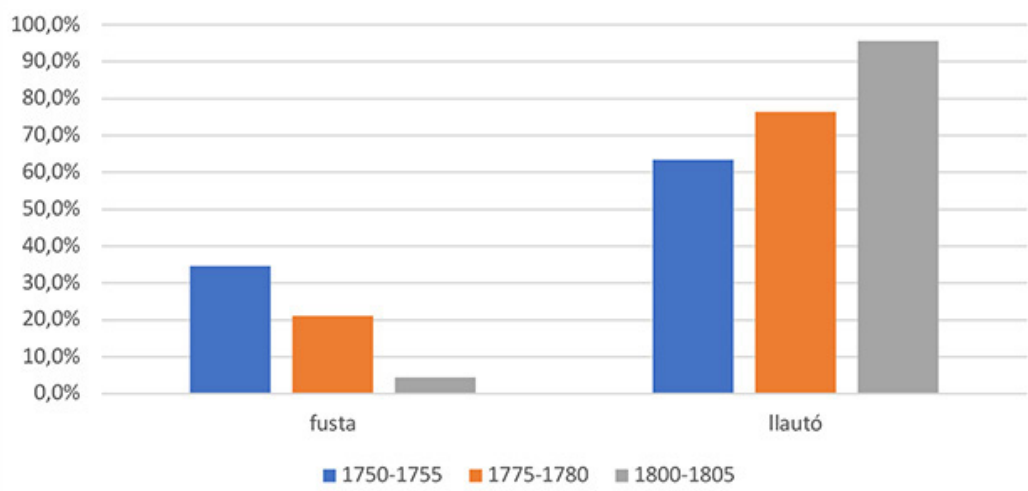

Si ultrapassem els límits de les terres gironines i comparem els indicadors de consum dels treballadors selvatans amb els que presenten els pagesos sense terra i petits propietaris (tenidors de menys de 5 ha) penedesencs per al període $1770-1790,{ }^{29}$ podem observar, de nou, que en els nostres inventaris les xifres són sensiblement més modestes. La mitjana de llençols era de 8 i 10 en els respectius inventaris dels petits pagesos penedesencs i, en canvi, la nostra xifra mediana per al període 1800-1805 se situa en 5. Pel que fa als tovallons, tant els pagesos sense terra com els petits propietaris en tenien una mitjana

28. Serramontmany (2015: 256).

29. Moreno (2007: 48-57). 
de 4. La mateixa xifra assolim en la nostra mostra d'inventaris per als anys 1750-1755, però s'acaba reduint fins a 3 en els períodes posteriors.

Fins ara hem anat apuntant que l'evolució del consum de béns tèxtils (llençols, estovalles, tovallons, tovalloles, camises, etc.) no mostra un dinamisme excessiu, especialment quan ho comparem amb altres regions i territoris. Ara bé, si observem amb una mica més de deteniment les pautes de consum tèxtil dels treballadors selvatans, i més concretament del tipus de fibra, sí que detectem alguns canvis que val la pena esmentar (gràfic 4).

Al llarg dels tres períodes analitzats hi ha una hegemonia molt clara dels teixits de llenç, que són els de menor qualitat, amb percentatges sempre al voltant del 75\%; és a dir, tres de cada quatre peces de roba (tant d'ús domèstic com personal) eren elaborades a partir d'aquest tipus de fibra. No són, però, xifres molt diferents de les que es detecten en altres indrets de Catalunya. A partir d'una mostra de 1.845 inventaris de Figueres, Mataró i Igualada (on els inventaris de jornalers només representen el 12\% del total), observem que al llarg del segle xviı el consum de teixits de llenç era de l'ordre del $62-80 \%{ }^{30}$ A més, dins dels diferents tipus de gèneres de llenç que localitzem en els teixits dels nostres inventaris es pot observar una disminució significativa dels d'un a qualitat més ordinària (els d'estopa). En efecte, si comparem el tipus de fibra amb què s'elaboren els llençols (quadre 6), podem constatar que en el període 1750-1755 els elaborats totalment o parcialment amb estopa representen el 28,3\% de la mostra; en els dos períodes següents la xifra s'ha reduit al 14\%. Parallelament, tres de cada deu llençols dels anys 1800-1805 foren elaborats a partir de teixits purs de bri, mentre que en els dos períodes anteriors la xifra no arribava ni al $10 \%$.

\section{Gràfic 4 \\ Evolució de les pautes de consum tèxtil a partir del tipus de fibra}

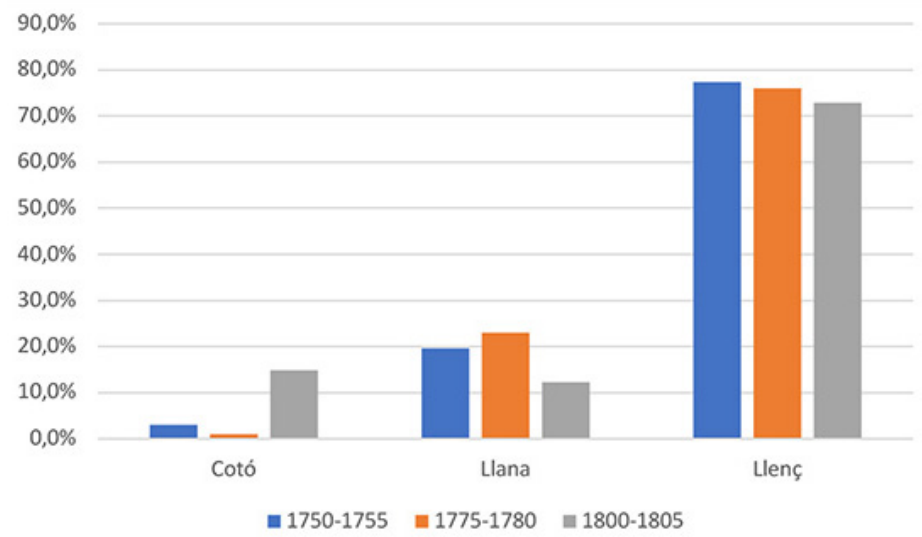

30. Torra (1999: 94). 


\section{Quadre 6. Evolució del tipus de teixit amb què s'elaboren els llençols}

\begin{tabular}{|l|c|c|c|}
\hline \multicolumn{1}{|c|}{ Material } & $\begin{array}{c}\mathbf{1 7 5 0 - 1 7 5 5} \\
(\boldsymbol{n = 9 2 )}\end{array}$ & $\begin{array}{c}\mathbf{1 7 7 5 - 1 7 8 0} \\
(\boldsymbol{n = 9 9 )}\end{array}$ & $\begin{array}{c}\mathbf{1 8 0 0 - 1 8 0 5} \\
(\boldsymbol{n}=\mathbf{1 4 4})\end{array}$ \\
\hline Bri i borràs & $43,5 \%$ & $24,2 \%$ & $45,8 \%$ \\
\hline Borràs & $20,7 \%$ & $44,4 \%$ & $9,0 \%$ \\
\hline Estopa & $19,6 \%$ & $6,1 \%$ & $14,6 \%$ \\
\hline Bri i estopa & $8,7 \%$ & $8,1 \%$ & $0,0 \%$ \\
\hline Bri & $7,6 \%$ & $6,1 \%$ & $30,6 \%$ \\
\hline Fil de borràs & $0,0 \%$ & $3,0 \%$ & $0,0 \%$ \\
\hline Cànem i borràs & $0,0 \%$ & $8,1 \%$ & $0,0 \%$ \\
\hline
\end{tabular}

No localitzem en els inventaris de treballadors cap peça tèxtil de seda, de manera que podem considerar el cotó i la llana com les fibres de qualitat superior a què accedien els protagonistes de la nostra mostra. Podria semblar, en observar el gràfic 4, que a principis del segle xix el cotó estava substituint la llana. La realitat, però, és que l'un i l'altra tipus de filatura segueixen trajectòries diferents al llarg dels tres períodes analitzats. De fet, la quantitat de peces de llana es manté bastant estable al llarg dels tres talls cronològics. Es tracta principalment de peces destinades a la indumentària personal: calces, calçons, gambetos i jupes en el cas dels homes, faldilles i caputxes en el de les dones. El més habitual era que fossin de cordellat, tot i que també localitzem algunes varietats de baieta, estamenya o burell. Pel que fa a la roba de la llar, només les flassades solien ser de llana i en algunes ocasions trobem també algunes estovalles de cordellat.

Si trobem la llana principalment entre els teixits que podríem considerar de l'aixovar personal, les peces de cotó estan íntimament relacionades amb l'aixovar domèstic. El seu augment en els inventaris de principis del segle xix s'emmarca en un context de creixement generalitzat de tot tipus de peces de roba de la llar. La majoria continuaven essent elaborades a partir de fibres de llenç, però una petita part d'aquestes ho eren, totalment o parcialment, a partir de cotó. Es tracta bàsicament d'estovalles i tovallons, normalment a partir d'una barreja de cotó i bri i en algunes ocasions (poques) exclusivament de cotó. Només en un inventari, el del treballador de Santa Coloma de Farners Joseph Frigola, hi trobem una peça de teixit d'indiana. Es tracta d'unes faldilles de la seva difunta esposa. És també l'única peça d'indumentària personal elaborada amb fibres de cotó.

Tal com es pot apreciar al quadre 7, el consum de teixits de cotó era molt desigual entre els treballadors selvatans de principis del segle xIx. Es concentrava bàsicament en els treballadors econòmicament més reeixits i que ja havien adquirit l'etiqueta socioprofessional de menestral. ${ }^{31}$ Un sol individu, Vicenç Llach, ja acaparava 35 de les 65 peces de cotó. 90 i 91.

31. Dediquem el següent apartat del treball a aquests treballadors enriquits. Vegeu, per exemple, el quadre 8 a les $\mathrm{p}$. 
Les 30 restants se les repartien entre 5 individus més; els 22 treballadors restants, per tant, no tenien cap teixit de cotó en els seus inventaris.

\section{Quadre 7 \\ Relació dels inventaris del període 1800-1805 on s'han localitzat teixits de cotó}

\begin{tabular}{|l|l|l|c|l|l|}
\hline \multicolumn{1}{|c|}{ Ofici } & Nom i cognoms & \multicolumn{1}{|c|}{$\begin{array}{c}\text { Municipi de } \\
\text { residència }\end{array}$} & Quantitat & Objecte & Material \\
\hline Menestral & Vicenç Llach & la Cellera de Ter & 30 & tovalló & cotó i bri \\
\hline Menestral & Vicenç Llach & la Cellera de Ter & 5 & estovalles & cotó i bri \\
\hline Menestral & Joan Rouras & la Cellera de Ter & 11 & tovalló & fil i cotó \\
\hline Bracer & Joan Fàbregas & Anglès & 10 & tovalló & cotó i bri \\
\hline Bracer & Joan Fàbregas & Anglès & 2 & estovalles & cotó i bri \\
\hline Bracer & Joseph Fontseca & Arbúcies & 3 & tovalló & cotó i bri \\
\hline Bracer & Joseph Fontseca & Arbúcies & 1 & tovallola & cotó i bri \\
\hline Treballador & Segismon Salomí & Caldes de Malavella & 2 & tovalló & fil i cotó \\
\hline Treballador & Joseph Frigola & $\begin{array}{l}\text { Santa Coloma de } \\
\text { Farners }\end{array}$ & 1 & faldilles & indiana \\
\hline
\end{tabular}

En el treball citat anteriorment de Lídia Torra, que estudià les pautes de consum tèxtil de la Catalunya del segle xviII, l'autora posava de manifest que la gran proporció de teixits de llenç existent en els inventaris no es correlacionava amb l'anàlisi dels estocs de les botigues de teles, on eren presents en una proporció molt inferior. Fruit d'això, es plantejava com a hipòtesi si totes aquestes peces de qualitat inferior s'adquirien a través de canals més informals, com podien ser els mercats ambulants i on, per tant, tenia un pes més important la filatura domèstica a petita escala. ${ }^{32}$ Disposem, per als períodes estudiats, de l'inventari post mortem d'un teixidor de lli amb botiga. ${ }^{33}$ Extreure qualsevol conclusió d'un sol cas seria molt agosarat, però hem de dir que coincideix amb allò observat per Lídia Torra, ja que si bé a la seva botiga el llenç tenia un pes important (no en va s'etiquetava l'individu com a teixidor de lli), no ho era en la proporció que es detecta als inventaris. Els estris de treball eren 1 torn, 3 telers i 10 pintes. Pel que fa a l'estoc de teles, trobem

32. Torra (1999: 94-95). Així mateix i en relació amb la comercialització i el consum de robes de baixa qualitat, ha estat ben estudiada per a Anglaterra en els diversos treballs de Beverly Lemire (1988: 1-24; 1991: 67-82; 1997), entre d'altres.

33. També gaudim de l'inventari de Jaume Jalpí, comerciant de Santa Coloma de Farners, redactat el 9 de novembre de 1780 amb motiu del matrimoni de la seva pubilla, Maria Jalpí, amb Dalmau Fàbregas. Al final de tot es fa referència a «tres casetas que comprà [...] las quals vuy serveixen per la fabrica de teles». No tenim, però, l'inventari de l'interior d'aquestes casetes, que ens aportaria de ben segur una valuosa informació. Es tracta, molt possiblement, de la «fabrica de lienzos de Dalmau Fabregas y Jalpi», on s'utilitzaven «unos 40 telares», segons el que relata Francisco de Zamora quan passa per Santa Coloma de Farners l'any 1790 (1973: 303). 
d'entrada 50 canes de cànem i llana barrejades, 25 canes de drap de bri i 12 canes de llana filada. A continuació i dins de 6 sacs, trobem 12 lliures de fil de cànem i 20 més de cànem pentinat. Aproximadament, doncs, un $58 \%$ de les teles que tenia eren de llenç i un $42 \%$ de llana. Finalment, el darrer objecte que s'inventaria a la botiga és una «vela de anar a parar a la plaça», cosa que significa que aquest teixidor comerciava com a mínim una part de la seva producció a través d'aquesta xarxa de petits mercats ambulants (normalment de periodicitat setmanal), com seria el cas del de Santa Coloma de Farners, que se celebrava, igual que avui en dia, els dilluns. ${ }^{34}$

Parallelament, hem buscat tots els rastres de manufactura tèxtil domèstica, per veure fins a quin punt les famílies treballadores selvatanes podien produir les seves pròpies peces de llenç i/o comerciar-les com a complement de l'economia domèstica. Al llarg de la segona meitat del segle xviII, en aproximadament una quart part de les llars treballadores hi havia estris destinats a la filatura domèstica (torns, fusos, filoses, aspis, debanells, etc.). La majoria d'aquests treballadors tenien també alguna petita porció de peces de llenç, que podrien servir per a ús exclusivament domèstic.

Ara bé, hi ha alguns inventaris de treballadors de la terra en què la quantitat de material destinat a la manufactura tèxtil és significativa, i més tenint en compte que sovint es tracta d'inventaris molt modestos, en els quals en general ja hi ha pocs objectes de qualsevol tipus. Un bon exemple seria el del bracer de la Cellera de Ter, Josep Vinyas, en l'inventari de béns del qual, que es redactà el 19 de gener de 1750, hi localitzem fins a 36 cabdells de fil de borràs, juntament amb 2 peces de drap prim i 2 de drap gros. En l'inventari de béns de Pere Oller Doltra, també bracer però en aquest cas de Riudarenes, que es feu el 4 de desembre de 1778, localitzem al seu dormitori: 15 canes (uns 23 m) de drap de borràs, 9 rams de fil de bri i 8 cabdells de fil d'estopa. Josep Guell, bosquerol d'Osor, l'inventari post mortem del qual es va redactar l'abril de 1780, tenia també en el seu dormitori 13 lliures de «canem sens pentinar» 10 més d'«estopa filada» (5,2 i 4 kg, respectivament). Ben a prop trobem també un «torn de peu». Tota la seva indumentària personal (com a mínim la que s'inventaria) era de llana: 3 gambetos de cordellat, 2 jupes i 2 calces també de cordellat i 1 «armilla» de retina.

Totes aquestes partides de fils i teixits presents en les llars treballadores són petites, sobretot si les comparem amb els estocs que tenia a la seva botiga el teixidor de lli mencionat més amunt, i serien segurament minúscules si les poguéssim comparar amb les d'algun botiguer o comerciant de teles. Hi volíem posar l'accent per insistir en el fet que, atès que es tracta d'inventaris petits i modestos, amb molts pocs objectes, i, per tant, de famílies amb un patrimoni reduit, moltes de les quals vivien segurament a prop del límit de la subsistència, el fet de conservar diversos quilos de teixits de llenç ens indica, a parer nostre, que per a moltes d'aquestes famílies la manufactura tèxtil domèstica havia de tenir un pes important, ja fos per a l'autoabastiment de roba de baixa qualitat (i estalviar-se, per tant, la despesa d'haver-les de comprar), ja fos per comerciar-les a través d'aquestes xar-

34. Així ho explica Francisco de Zamora en el seu dietari: «Tiene este pueblo unas 600 casas y un mercado cada lunes» (1973: 303). 
xes de mercats ambulants i canals més informals on es creu que circulaven precisament aquests tipus de teixits, complementant d'aquesta manera els ingressos familiars. ${ }^{35}$

\section{El sorgiment dels menestrals: una nova etiqueta per definir un nou grup social?}

Fins ara hem anat parlant dels inventaris dels treballadors selvatans sense explicar detalladament amb quines etiquetes socioprofessionals s'identificaven o, més ben dit, com els identificaven els seus hereus i successors en el cas dels inventaris post mortem, quan acudien al notari. Si bé les fonts oficials de l'època solien referir-se a ells com a «jornaleros», ${ }^{36}$ aquesta etiqueta no s'utilitza en el llenguatge notarial. La més habitual i comuna era, precisament, la de «treballador», tot i que en moltes ocasions també surten identificats com a «bracers». ${ }^{37}$ En la nostra àrea d'estudi i com el seu nom molt bé indica (la Selva), prenen també una importància especial els jornalers vinculats a les tasques forestals. És per això que en el grup dels «treballadors» també hi hem inclòs les dues etiquetes amb les quals se'ls identifica: «bosquerols» $\mathrm{i}$ «roders». ${ }^{38}$

Als inventaris del període 1800-1805 entra en joc una cinquena etiqueta per identificar alguns membres d'aquest collectiu: la de «menestral». No es tracta d'artesans, que és el que significa aquesta paraula a la resta de Catalunya, sinó de treballadors de la terra, i, més concretament i segons les darreres recerques, servia per identificar els treballadors enriquits. ${ }^{39}$ Es tracta, doncs, de petits pagesos sense mas i que, per tant, a la Catalunya Vella (és a dir, a la Catalunya dels masos) no es poden etiquetar pròpiament com a pagesos; però, en canvi, tampoc no són en sentit estricte jornalers, perquè sí que tenen i treballen una explotació agrícola familiar. Hem esmentat a l'inici d'aquest treball el cas de l'inventari del «pages o menestral» Aciscle Vicens, que vivia en una casa (no en un mas), però es definia la casa utilitzant els termes habituals per definir els masos, és a dir, acompanyada de les seves «terras honors y possessions». Serveix com un exemple molt clarificador del que es-

35. A Igualada, destacat nucli d'especialització protoindustrial tèxtil (Ferrer 2012: 199 i 205), entre finals del segle xvi i principis del xix un 29,3\% dels inventaris de famílies amb el cap de casa dedicat a un ofici agrícola disposaven d'equipaments destinats a la manufactura tèxtil, com ara telers i/o torns (Marfany 2020: 186).

36. És l'etiqueta que s'utilitza al cens de Floridablanca del 1787. A la llista de l'armament de 1795 hi trobem la de «jornaleros y criados».

37. La diferència entre «treballador» $\mathrm{i}$ «bracer» resulta complicada de determinar. El concepte de bracer sembla que fa referència al qui es guanya la vida amb els seus braços. L'estudi dels dots i dels inventaris dels uns i els altres no ens mostra cap patró de diferenciació clara. En tot cas, ells sí que sabien quina era la diferència. Sovint es poden trobar en la documentació notarial individus que s'etiqueten com a «vuy treballador, antes brasser», o a l'inrevés: «vuy brasser, antes treballador».

38. L'ofici de «roder», que podria generar confusió entre els menys familiaritzats amb el terme, no és el del que elabora rodes, sinó rodells. Es tracta d'uns cèrcols de fusta molt utilitzats per a l'elaboració de botes i altres embalatges de fusta, que va representar un tipus d'aprofitament forestal molt estès i practicat als boscos de les Guilleries (Rams 2002: 162-173).

39. En relació amb la gènesi i el seguiment dels primers «menestrals» gironins, vegeu Congost (2014: 165-191) i també Congost, Ros i Saguer (2016: 617-646). 
tem explicant: no estem davant d'una casa d'un treballador, com a molt amb un hort o una petita parcella de terra annexa, però tampoc no residia en una masia com a tal.

Al llarg de tot l'estudi hem anat esmentant contínuament l'existència d'un marcat procés de diferenciació socioeconòmica en el si del collectiu dels treballadors pel que fa als inventaris del període 1800-1805. A hores d'ara no sorprendrà el lector que afirmem que els responsables d'aquesta polarització són precisament els menestrals. Podríem mostrar-ne molts exemples. Al quadre 8 hem seleccionat dos indicadors de consum que penetraren a les llars de les famílies humils al llarg del segle xvin, especialment durant la segona meitat: els tovallons i les forquilles. Hem ordenat de més a menys, en funció de la quantitat total d'aquests dos objectes, els inventaris de treballadors redactats a les notaries selvatanes objecte del nostre estudi. El resultat no deixa lloc a gaires interpretacions: els menestrals jugaven en una altra lliga. En un període en què la mediana de tovallons i forquilles era, respectivament, de 3 i 5 unitats, ${ }^{40}$ els menestrals ja en tenien més de 20 . I no només és un tema de quantitat, sinó també de qualitat; o, en tot cas, del material amb què eren elaborats. Això s'observa clarament en el cas dels tovallons. En uns temps en què el que més abundava eren els teixits de llenç, són aquests menestrals els que acaparen majoritàriament les peces de cotó. 11 dels 26 tovallons de Joan Rouras eren de fil i cotó, i 30 dels 36 que tenia el seu veí Vicens Llach estaven fets de cotó i bri. En el cas dels inventaris de bracers i treballadors, en canvi, són peces pures de llenç (bri i/o borràs). És a dir, tant des d'una perspectiva quantitativa com qualitativa, els menestrals presenten una taxa de consum de tovallons clarament superior a la del conjunt del collectiu.

\section{Quadre 8}

\section{Quantitat de tovallons i forquilles localitzats en els inventaris del període 1800-1805}

\begin{tabular}{|l|l|l|c|c|}
\hline \multicolumn{1}{|c|}{ Ofici } & \multicolumn{1}{|c|}{ Nom i cognoms } & \multicolumn{1}{c|}{ Municipi de residència } & Tovallons & Forquilles \\
\hline Menestral & Vicenç Llach & la Cellera de Ter & 36 & 24 \\
\hline Menestral & Joan Rouras & la Cellera de Ter & 26 & 21 \\
\hline Menestral & Aciscle Vicens & Llagostera & 23 & 0 \\
\hline Bracer & Esteve Valls & la Cellera de Ter & 3 & 15 \\
\hline Bracer & Joan Fabregas & Anglès & 10 & 6 \\
\hline Treballador & Salvador Fabregues & Santa Coloma de Farners & 7 & 9 \\
\hline Treballador & Segismon Salomí & Caldes de Malavella & 2 & 8 \\
\hline Bracer & Joan Oliveras & la Cellera de Ter & 6 & 0 \\
\hline Bosquerol & Joan Basset & Viladrau & 5 & 1 \\
\hline Treballador & Joseph Joglar & Santa Coloma de Farners & 1 & 5 \\
\hline Treballador & Salvador Estrach & Santa Coloma de Farners & 1 & 5 \\
\hline
\end{tabular}

40. Vegeu el quadre 5 , p. 83. 


\begin{tabular}{|l|l|l|c|c|}
\hline Treballador & Narcís Jaumot & Llagostera & 0 & 5 \\
\hline Treballador & Jaume Marzó & Vidreres & 2 & 2 \\
\hline Treballador & Joan Casanovas & Santa Coloma de Farners & 0 & 4 \\
\hline Bracer & Joseph Fontseca & Arbúcies & 3 & 0 \\
\hline Treballador & Salvador Rossell & Bescanó & 0 & 3 \\
\hline Bracer & Joan Fàbrega & Sant Hilari Sacalm & 2 & 0 \\
\hline Treballador & Joseph Falgueras & Llagostera & 1 & 0 \\
\hline
\end{tabular}

Si estudiem el rol dels menestrals des de la perspectiva del paper que tenen en l'evolució de la relació dels treballadors amb la possessió de béns immobles (majoritàriament cases i terres), de nou podem constatar que són els principals responsables dels canvis i les bifurcacions que hem anat detectant i apuntant per als inventaris de principis del segle XIX.

Destaca en aquest aspecte i especialment l'inventari de Joan Rouras. És, de fet, el responsable que a la darrera columna del quadre 4 haguem pogut anotar algú amb més de 5 ha de terra. Vivia en una casa en propietat que tenia hort (plantat de cols), trull i bassa de desfer oli. Posseïa, a més, un total de 13 peces de terra d'allò més variades, de secà i de regadiu; vinyes i oliveres; alzines, castanyers i avellaners; algunes pomeres i altres arbres fruiters. La majoria de les terres les tenia al mateix municipi on residia, la Cellera de Ter, però també tenia alguna propietat a la localitat veina de Sant Julià del Llor i fins i tot una peça de terra d'11 mesurons «sembrada de mestall» a Fontcoberta.

L'altre menestral cellerenc, Vicenç Llach, no es quedava gaire lluny. Era propietari de dues cases, una amb era i l'altra amb una vessana de terra contigua. També posseïa, tot al mateix municipi de la Cellera, 7,5 vessanes de castanyers, 2 vessanes de vinya i oliveres i un hort on també hi havia diversos arbres fruiters. A Bonmatí hi tenia 2 vessanes més de vinya i oliveres. Pel que fa al tercer menestral, Aciscle Vicens, no sabem gaire cosa de les seves terres perquè, com hem dit, l'inventari fa una referència genèrica a les terres, honors i possessions inherents a la casa, com si es tractés d'un veritable pagès de mas.

Finalment, voldríem esmentar de nou l'inventari de Joan Rouras, ja que és possiblement un bon exemple del fet que estem assistint al naixement d'un nou grup social i econòmic. La vigília de Nadal de l'any 1805, «Anna Maria Rouras Bosch y Bonmatí, vidua deixada de Joan Rouras manastral del dit lloch» (de la Cellera) comença a redactar l'inventari acompanyada del notari d'Anglès. Es queden a mitges i el continuen a principis de febrer de l'any 1806. En la represa de l'inventari i sorprenentment, etiqueten el difunt Joan Rouras com a «bracer». Seria un insòlit procés de descens social el que hauria protagonitzat aquest difunt cellerenc l'hivern de 1805-1806, sobretot si tenim en compte que la primera estança que es descriu en la continuació de l'inventari és «lo quarto de la criada». Una mica més endavant, en «lo quarto de dalt ${ }^{41}$ hi trobem una «boteta petita per portar vi a los treballadors». Servei domèstic i un estri destinat a servir beguda als seus propis jornalers.

41. No és una dada banal, significa que la casa tenia més d'una planta. 
No cal que es preocupi excessivament el lector si tot plegat no encaixa gaire amb la idea preconcebuda que pot tenir del que era un proletari rural.

\section{Conclusions}

Al llarg de les pàgines precedents hem intentat mostrar que a través de l'atenta lectura i l'estudi dels inventaris post mortem dels treballadors de la terra és possible intuir i detectar canvis en els costums, les pautes de consum i també en les condicions vitals. Hem vist com eren les seves cases, per dins i per fora, quantes estances tenien, amb quina finalitat les utilitzaven i quins béns hi dipositaven. Això ens ha permès copsar que al llarg de la segona meitat del segle xvin anaren apareixent en les llars treballadores selvatanes alguns objectes que mig segle endarrere eren pràcticament desconeguts. Aquests nous objectes no només ens indiquen canvis en les modes o en els gustos, sinó que tenen en molts casos connotacions amb altres aspectes vitals (higièniques i/o alimentàries, com podria ser, per exemple, en els casos dels tovallons, les culleres i les forquilles).

Tots aquests canvis i transformacions que hem detectat són, tal com hem anat apuntant, relativament petits si els comparem amb els que es detecten, en estudis similars al nostre, per a altres regions de Catalunya. Ara bé, encara que certament es tracti de canvis més modestos, apunten igualment, a parer nostre, la hipòtesi que en els orígens del capitalisme agrari les classes subalternes rurals tingueren un paper menys passiu del que inicialment se'ls havia atribuit.

Conscients de les limitacions de la font i també del fet que treballem amb una mostra relativament petita (i dividida, a més, en tres talls temporals), ${ }^{42}$ hem intentat interpretar els resultats amb cautela i no magnificar canvis percentuals que bé podrien ser deguts a factors atzarosos. Per tal de palliar, ni que sigui parcialment, aquestes limitacions, al llarg del treball s'han anat succeint les taules i els gràfics amb el relat detallat d'alguns inventaris concrets. Considerem que en aquesta doble lectura alhora quantitativa i qualitativa rau una de les majors virtuts dels inventaris: si ens limitéssim a agregar dades i a sumar ítems, la «boteta petita per portar vi a los treballadors» de Joan Rouras no seria altra cosa que un objecte més en una llista de béns. Així mateix, si declinéssim l'anàlisi quantitativa i llegíssim cadascun dels inventaris gairebé com si es tractés d'una peça literària, se'ns escaparien molts canvis subtils que, un cop agregats, ens acaben dibuixant tendències prou sòlides. La suma de tot plegat és precisament el que ens permet formular les hipòtesis de treball que guiaran les nostres recerques futures.

Voldríem insistir, amb el risc de començar a sonar repetitius, en una d'aquestes hipòtesis: en vista dels resultats obtinguts, creiem que estem davant el sorgiment d'un nou grup social format a partir de treballadors enriquits. Homes i dones que en un context de proletarització de la societat (degut en bona part a la puixança demogràfica característica

42. Vegeu la nota al peu núm. 11, p. 71. 
del segle xviII), ${ }^{43}$ lluny d'empobrir-se, van ser capaços de millorar les seves condicions de vida i d'accés a la terra. Parallelament, també transformaren les seves pautes de consum.

Una de les característiques de les societats europees d'inicis dels temps moderns és que no eren ni prou tancades per impedir l'ascens social ni prou obertes ni meritocràtiques per fer que les aparences no importessin. En aquest context, pretendre emular i imitar els grups socials superiors al teu tindria tot el sentit. ${ }^{44}$ En la Catalunya dels masos existia una frontissa molt clara pel que fa als límits de la possibilitat d'emulació: la possessió d'un mas. En absència d'aquest, hom no podia ser considerat pagès, independentment de quines fossin les seves riqueses i possessions. Aquests homes i dones, que van decidir definir-se com a menestrals, ho feren perquè es veien a ells mateixos diferents de com eren abans i, per tant, sentien la necessitat d'etiquetar-se d'una manera diferent. No es podien anomenar pagesos, encara que la vídua d'Aciscle Valls ho intentés, ja que no tenien un mas, però ja no eren uns «bracers» que vivien de vendre la força de treball dels seus «braços». Ara tenien quelcom per «menester», és a dir, per administrar, i per tant eren, de cap a peus, uns autèntics «menestrals».

\section{Bibliografia consultada}

AlLen, Robert C. (2015). «The high wage economy and the industrial revolution: a restatement», The Economic History Review, núm. 68(1), p. 1-22.

Aulen, Robert C. (2013). Historia económica mundial: una breve introducción. Madrid: Alianza.

Aulen, Robert C. (2009). The British industrial revolution in global perspective. Cambridge: Cambridge University Press.

AlLEN, Robert C. (2001). «The great divergence in European wages and prices from the Middle Ages to the First World War», Explorations in Economic History, núm. 38(4), p. $411-447$.

AluEN, Robert C. (2000). «Economic structure and agricultural productivity in Europe, 13001800», European Review of Economic History, núm. 4(1), p. 1-25.

Aluen, Robert C.; WeisDorf, Jacob (2011). «Was there an "industrious revolution" before the industrial revolution? An empirical exercise for England, c. 1300-1830», The Economic History Review, núm. 64(3), p. 715-729.

Brewer, John; Porter, Roy (eds.) (2013). Consumption and the World of Goods. Londres: Routledge.

ClaRK, Gregory. (2007). «The long march of history: Farm wages, population, and economic growth, England 1209-1869», The Economic History Review, núm. 60(1), p. 97-135.

CLARK, Gregory (2005). «The condition of the working class in England, 1209-2004», Journal of Political Economy, núm. 113(6), p. 1307-1340.

43. Ferrer (2007: 17-68).

44. De Vries (2009: 68). 
Clark, Gregory (2001). «Farm wages and living standards in the Industrial Revolution: England, 1670-1869», The Economic History Review, núm. 54(3) p. 477-505.

CoDina, Jaume (1998). El gir de 1750: origen y creixement modern de la població. Lleida: Pagès.

Congost, Rosa (2014). «Més enllà de les etiquetes. Reflexions sobre l'anàlisi dels grups socials humils. La regió de Girona (1770-1850)», Recerques: Història, Economia, Cultura, núm. 68, p. 165-191.

Congost, Rosa (2010). «El declivi dels capítols matrimonials en el segle xx». Dins Rosa Ros (ed.). Els capitols matrimonials: Una font per a la bistòria social. Girona: Associació d'Història Rural de les Comarques Gironines / Centre de Recerca d'Història Rural, p. $89-102$.

Congost, Rosa (2007a). «Sobre casos intermediaris i creixements espontanis. Els treballadors de la regió de Girona», Estudis d'Història Agrària, núm. 20, p. 133-154.

Congost, Rosa (2007b). Tierras, leyes, historia: Estudios sobre «la gran obra de la propiedad». Barcelona: Crítica.

Congost, Rosa (1997). «De pagesos a hisendats: reflexions sobre l'anàlisi dels grups socials dominants. La regió de Girona (1780-1840)», Recerques: Història, Economia, Cultura, núm. 35, p. 51-72.

Congost, Rosa; Ros, Rosa (2018). «Els inventaris de la gent humil: els treballadors de la regió de Girona al segle XviI». Dins Belén Moreno (ed.). Els inventaris post mortem: Una font per a la bistòria econòmica i social. Girona: Associació d'Història Rural de les Comarques Gironines / Centre de Recerca d'Història Rural, p. 63-86.

Congost, Rosa; Ros, Rosa (2013). «Change in society, continuity in marriage: an approach to social dynamics through marriage contracts (Catalonia, 1750-1850)», Continuity and Change, núm. 28(2), p. 273-306.

Congost, Rosa; Ros, Rosa; Saguer, Enric (2016). «Beyond life cycle and inheritance strategies: The rise of a middling social group in an Ancien Régime society (Catalonia, eighteenth Century)», Journal of Social History, núm. 49(3), p. 617-646.

De VRIES, Jan (2009). La revolución industriosa: Consumo y economía doméstica desde 1650 basta el presente. Barcelona: Crítica.

DE VRIES, Jan (1994). «The industrial revolution and the industrious revolution», Journal of Economic History, núm 54(2), p. 249-270.

Esteve, Eulàlia (2011). Homes, terres, cases i masos del Baix Empordà: Estudi de les transformacions socials als segles XVIII $i$ XIX (Tesi doctoral). Girona: Universitat de Girona.

FERRER, Llorenç (2012). «El creixement divers de la Catalunya del segle xviII. Protoindustrialització?», Catalan Historical Review, núm. 5, p. 195-209.

FERRER, Llorenç (2007). «Una revisió del creixement demogràfic de Catalunya en el segle XviI a partir dels registres parroquials», Estudis d'Història Agrària, núm. 20, p. 17-68.

FonTana, Josep (2019). Capitalisme i democràcia, 1756-1848: Com va començar aquest engany. Barcelona: Edicions 62.

Humphries, Jane; Weisdorf, Jacob (2019). «Unreal wages? Real income and economic growth in England, 1260-1850», The Economic Journal, núm. 129(623), p. 2867-2887. 
Lemire, Beverly (1997). Dress, culture and commerce: The English clothing trade before the factory, 1660-1800. Basingstoke: Macmillan.

LEmire, Beverly (1991). «Peddling fashion: salesmen, pawnbrokers, taylors, thieves and the second-hand clothes trade in England, c. 1700-1800», Textile History, núm. 22, p. 67-82.

LEmiRe, Beverly (1988). «Consumerism in preindustrial and early industrial England: The trade in secondhand clothes», The Journal of British Studies, núm. 27(1), p. 1-24.

Marfany, Julie (2020). Terra, protoindústria i població a Igualada, c. 1680-1829: Una via catalana de transició al capitalisme? Girona: Associació d'Història Rural de les Comarques Gironines / Centre de Recerca d'Història Rural.

Marfany, Julie (2010). «Els canvis en el costum: Igualada en el segle xviI». Dins Rosa Ros (ed.). Els capitols matrimonials: Una font per a la bistòria social. Girona: Associació d'Història Rural de les Comarques Gironines / Centre de Recerca d'Història Rural, p. 105-113.

Mas, Josep (2016a). «Canvis i continuïtats a l'àrea de Santa Coloma de Farners. Una aproximació a partir dels capítols matrimonials (1750-1805)», Mestall. Butlletí de l'Associació d'Història Rural, núm. 40, p. 18.

Mas, Josep (2016b). «Transformacions socioeconòmiques a l'àrea de Santa Coloma de Farners (la Selva). Una aproximació a partir dels capítols matrimonials (1750-1805)», Quaderns de la Selva, núm. 28, p. 71-85.

Mckendrick, Neil; Brewer, John; Plumb, John H. (ed.). The Birth of the Consumer Society: The Commercialization of Eighteenth-Century England. Bloomington: Indiana University Press.

Moreno, Belén (ed.) (2018). Els inventaris post mortem: Una font per a la història econòmica $i$ social. Girona: Associació d'Història Rural de les Comarques Gironines / Centre de Recerca d'Història Rural.

MoRENo, Belén (2018). «Els inventaris post mortem catalans a l'època moderna: característiques, punts forts i punts febles». Dins Belén Moreno (ed.). Els inventaris post mortem: Una font per a la bistòria econòmica $i$ social. Girona: Associació d'Història Rural de les Comarques Gironines / Centre de Recerca d'Història Rural, p. 37-61.

Moreno, Belén (2007). Consum i condicions de vida a la Catalunya moderna: El Penedès, 1670-1790. Vilafranca del Penedès: Edicions i Propostes Culturals Andana.

Pomeranz, Kenneth (2000). The Great Divergence: China, Europe, and the Making of the Modern World Economy. Princeton: Princeton University Press.

Rams, Emili (2002). «Els oficis perduts dels bosquerols de les Guilleries», Revista d'Etnologia de Catalunya, núm. 20, p. 162-173.

Roche, Daniel (1991). La culture des apparences: une histoire du vêtement (xvile-xviIe siècle). París: Fayard.

Ros, Rosa (2010). «Capítols vilatans, capítols rurals. Els capítols matrimonials de Sant Feliu de Guíxols i la Vall d'Aro (1780-1860)». Dins Rosa Ros (ed.). Els capitols matrimonials: Una font per a la història social. Girona: Associació d'Història Rural de les Comarques Gironines / Centre de Recerca d'Història Rural, p. 115-132. 
SerRamontmany, Albert (2015). Nivells de vida, dinàmiques socials i canvi històric: L'àrea de Besalú, 1750-1850 (Tesi doctoral). Girona: Universitat de Girona.

TorRA, Lídia (1999). «Pautas de consumo textil en la Cataluña del siglo xvII. Una visión a partir de los inventarios post-mortem». Dins Jaume Torras i Bartolomé Yun (dirs.). Consumo, condiciones de vida y comercialización: Cataluña y Castilla, siglos xVII-XIX. Valladolid: Junta de Castilla y León, Consejería de Educación y Cultura, p. 89-105.

TORRAS, Jaume; Yun, Bartolomé (dirs.) (1999). Consumo, condiciones de vida y comercialización: Cataluña y Castilla, siglos xVII-XIX. Valladolid: Junta de Castilla y León, Consejería de Educación y Cultura.

TORRAS, Jaume (2010). «Jan De Vries, La revolución industriosa. Consumo y economía doméstica desde 1650 hasta el presente, Barcelona, Crítica, 2009, 518 pp.», Revista de Historia Industrial, núm. 19, p. 181-183.

Vотн, Hans-Joachim (2001). «The longest years: new estimates of labor input in England, 1760-1830», The Journal of Economic History, núm. 61(4), p. 1065-1082.

Vотн, Hans-Joachim (2000). Time and work in England 1750-1830. Oxford: Clarendon Press, p. 77-82.

WeATHERILL, Lorna (1988). Consumer behaviour and material culture in Britain, 1660-1760. Londres: Routledge.

Wiluamson, Jeffrey G. (2012). Comercio y pobreza: Cuándo y cómo comenzó el atraso del Tercer Mundo. Madrid: Planeta.

Zamora, Francisco de (1973). Diario de los viajes hechos en Cataluña. Barcelona: Curial. 